\title{
Making sense of Literary Works through Customised Digital Books
}

\author{
Kara Mostefa-Boussena Leila \\ Department of English,Faculty of Foreign Languages, \\ Hassiba Ben Bouali University, \\ Chlef, Algeria
}

\begin{abstract}
The purpose of this article is to highlight the integration of electronic books besides paper books into literature curriculum in English as a Foreign Language Context (EFL). It aims at providing ideas and strategies to be integrated within the digitised version of a literary work and to question their effectiveness on learners' understanding, engagement and involvement in the learning process. To address this issue, a customised digitised play was implemented with a group of forty undergraduates reading for a BA of English. At the end of the play study, Students' questionnaire was collected and its analysis revealed a positive feedback. Participants expressed their satisfaction towards this technology and expressed their willingness to see this pedagogy generalised to the study of all literary works. Therefore, integrating customised digital books in literature curriculum is recommended as a facilitating and motivational pedagogy in an EFL context. However, technical difficulties were met and a need for continuous technical support proved to be obligatory in case of generalisation and application of this method to all compulsory literary works.

Keywords: customized digital books, literature curriculum, motivating, understanding, efl context

Cites as: Kara Mostefa, B.L. (2018). Making sense of Literary Works through

Customised Digital Books. Arab World English Journal for Translation \& Literary

Studies, 2 (4), 164-176.

DOI: http://dx.doi.org/10.24093/awejtls/vol2no4.12
\end{abstract}

